\title{
The Power Structure Relationship Handball Athletes using Sociometry
}

\author{
Wiga Nurlatifa Romadhoni ${ }^{1}$, Nasuka Nasuka ${ }^{2}$, Purwono Sidik Permono ${ }^{3}$ \\ \{wiganurlatifa@mail.unnes.ac.id ${ }^{1}$, nasuka@mail.unnes.ac.id² ${ }^{2}$, purwonosidik@mail.unnes.ac.id ${ }^{3}$ \}
}

Universitas Negeri Semarang, Indonesia ${ }^{123}$

\begin{abstract}
This research is based on the fact that athletes can make choices even in interpersonal relationships. The data in this study were obtained from 15 male handball athletes in Central Java, Indonesia. In general, the interpersonal relationship and cohesiveness between athletes is quite wide seen from the selection results on the sociogram. Even though there were several team members who fell out of the overall communication structure. Although based on the choice matrix and index selection, there were three athletes who got a zero index selection score where none of the three athletes chose to be friends during training or to be the leader or captain of the Handball male team. It is expected that over time and the development of the team, more athletes will be selected as team leaders and enter into subgroups that have average popularity.
\end{abstract}

Keywords: sociometry, sports team, assessment power structures relationship.

\section{Introduction}

Sports clubs are one of the places where the process of activities outside the formal education process is carried out [1]. The sports club is also a place for athletes to develop their abilities in technical, physical, and even social skills [2]. With regard to social aspects, many studies have discussed the relationship between the effectiveness of an environment in a particular sport, its relationship and activities even with athletes' participation [3]. The activities of a sports team require cooperation, support, harmonization and sportsmanship, therefore it is logical to expect the transfer of these values to the social environment of sports participants [4]. Good harmonization of team members or players in an interpersonal relationship leads to success in terms of cooperation in the field. Knowledge of the relationships between individuals on a sports team can be a valuable source of information for coaches [5]. The most important pedagogical task in selecting members of a sports team is how to create a harmonious and pleasant social environment for the players psychologically [6]. In addition, the cohesion of a sports team is very important in the development of team performance, therefore in a team or group we can find positive relationships as a sympathy, friendship and cooperation from good work efficiency [7]. The association with handball, with knowledge of the factors that influence interpersonal relationships, enables the handball coach or athlete to influence them to eliminate unwanted behavior. In addition, thanks to the awareness of forming and monitoring the right attitude in the team, the coach is able to improve the interpersonal situation of a player as well as in the team [8]. By doing so, the general atmosphere within the handball team will improve, so that it is correlated with the effectiveness of team activities in achieving the highest achievement goals. Handball itself is a 
team sport that is included in the game sport category. Besides being easy to learn, handball is based on natural human motor movements, making it possible to quickly become popular in the world [9]. In measuring the relationship between athletes, a method is needed that can be used to determine the social structure and communication between the athletes. Overall, the relationship between athletes and the cohesiveness between athletes is more oriented to the responsibility of the athletes themselves in relation to their performance on the field [10]. In this regard, sociometry is used as a method that has been widely used to measure both the social structure, communication and interpersonal relationships of a group [11]. The main objective of this study was to determine the relationship characteristics of athletes and group structure on the male handball team, especially when determining training partners and team leaders. In handball, the interpersonal relationship factor is very important in building the social structure of the team so that it allows the creation of the right conditions for a team to achieve the highest goals [12].

\section{Material and Methods}

In this study using sociometry as a method used to assess the characteristics of the relationship between athletes based on the principles and methods set out in the work of Wäsche 2017, Herbison 2018, Timushkin 2018, Sopa 2018 and Dontsov 2018. The survey data in this study consisted of 15 athletes male handball. The survey data includes the questions asked in the following table.

Table 1. Questions for sociometry research.

\begin{tabular}{ll}
\hline Question? & Answer Options \\
\hline $\begin{array}{l}\text { Which of your team members would you choose } \\
\text { to spend time training with? }\end{array}$ & $\begin{array}{l}\text { Answer (symbolizes a strong desire to cooperate } \\
\text { with others) }\end{array}$ \\
\hline $\begin{array}{l}\text { If you weose } 3 \text { of your friends } \\
\text { would you choose } \text { ? }\end{array}$ & \\
$*$ choose 3 of your friends & Answer... \\
\hline
\end{tabular}

The instrument above is a development of a sociometric test previously conducted by Vashliaeva Irina Viktorovna, Volovik Tatiana Vladimirovna, and Shuraleva Natalia Nikolaevna with the research title "Sociometry of a Volleyball Team". The data collected by sociometric questionnaires is still difficult to analyze and understand (read) if it has not been processed. In order for the sociometric data to be easy to understand, the data is presented in tabular form (sociometric matrix) and image form (sociogram).

After the sociometric questionnaire was filled in, then it was collected and processed to obtain an overview of the data. The research data will then be analyzed by analyzing the index, compiling tabulation tables, and making sociograms. Enter the data obtained from the sociometric questionnaire into the table provided that number 1 is for the first choice (1), number 2 for the second choice (2), number 3 for the third choice (3). The select direction tabulation data is calculated as follows: for the first choice (1) is given a score of three (3), for the second choice (2) is given a score of two (2), and the third choice is given a score of one (1). 


\section{Results and Discussion}

The next step is based on the data obtained in this study, then the next step is to analyze the responses from the athlete's answers by making a sociometric matrix. In table. 2 We assign research subjects with initial names in the first column and assign numbers consecutively.

Table 2. Sociometry Matrix

\begin{tabular}{|c|c|c|c|c|c|c|c|c|c|c|c|c|c|c|c|c|c|}
\hline \multirow{2}{*}{ Zo } & \multirow{2}{*}{$\begin{array}{c}\text { Subjec } \\
\text { ts } \\
\text { (voter) }\end{array}$} & \multirow[t]{2}{*}{ Age } & \multicolumn{15}{|c|}{ Selected } \\
\hline & & & 夏 & U. & $\sum_{\text {玄 }}$ & $\stackrel{\cup}{\longleftarrow}$ & $\Leftrightarrow$ & $\varangle$ & $\underline{v}$ & 四 & $\sum_{\sqrt[S]{ }}$ & $\vec{\alpha}$ & 光 & $\frac{1}{4}$ & 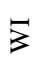 & $\sum$ & 合 \\
\hline & & & 1 & 2 & 3 & 4 & 5 & 6 & 7 & 8 & 9 & 10 & 11 & 12 & 13 & 14 & 15 \\
\hline 1 & DAF & 22 & $\mathbf{X}$ & & & & 3 & & 1 & & & 2 & & & & & \\
\hline 2 & PG & 19 & & $\mathbf{X}$ & & & 3 & & 1 & & & 2 & & & & & \\
\hline 3 & ANM & 18 & 3 & & $\mathbf{X}$ & & & 1 & & & & & & & & 2 & \\
\hline 4 & $\mathrm{AC}$ & 18 & 1 & & & $\mathbf{X}$ & & 2 & & & & & & 3 & & & \\
\hline 5 & $\mathrm{JF}$ & 20 & 3 & & & & $\mathbf{X}$ & & 1 & & & 2 & & & & & \\
\hline 6 & AA & 18 & & & 2 & & & $\mathbf{X}$ & & & & & 3 & & & & 1 \\
\hline 7 & RK & 25 & 2 & & & & & & $\mathbf{X}$ & 3 & & 1 & & & & & \\
\hline 8 & MEJ & 22 & 3 & & & & & & 1 & $\mathbf{X}$ & & 2 & & & & & \\
\hline 9 & SAM & 19 & & & & & 3 & & 1 & & $\mathbf{X}$ & 2 & & & & & \\
\hline 10 & $\mathrm{RP}$ & 23 & 2 & & & & 3 & & 1 & & & $\mathbf{X}$ & & & & & \\
\hline 11 & DW & 21 & & & & 2 & 1 & & & 3 & & & $\mathbf{X}$ & & & & \\
\hline 12 & AK & 23 & & & & & & & 1 & & & 2 & & $\mathbf{X}$ & & 3 & \\
\hline 13 & WI & 19 & 3 & & & & & & 1 & & & 2 & & & $\mathbf{X}$ & & \\
\hline 14 & MF & 20 & 3 & & & & & & 2 & & & 1 & & & & $\mathbf{X}$ & \\
\hline 15 & DP & 21 & 3 & & & & & & 1 & & & 2 & & & & & $\mathbf{X}$ \\
\hline \multicolumn{3}{|c|}{$\begin{array}{c}\text { Number of options } 1 \\
(\text { number } 1) * 3\end{array}$} & 3 & 0 & 0 & 0 & 3 & 3 & $\begin{array}{l}2 \\
7\end{array}$ & 0 & 0 & 6 & 0 & 0 & 0 & 0 & 3 \\
\hline \multicolumn{3}{|c|}{$\begin{array}{c}\text { Number of options } 2 \\
\quad(\text { number } 2) * 2\end{array}$} & 4 & 0 & 2 & 2 & 0 & 2 & 2 & 0 & 0 & 16 & 0 & 0 & 0 & 2 & 0 \\
\hline \multicolumn{3}{|c|}{$\begin{array}{c}\text { Number of options } 3 \\
(\text { number } 3)^{*} 1\end{array}$} & 6 & 0 & 0 & 0 & 4 & 0 & 0 & 2 & 0 & 0 & 1 & 1 & 0 & 1 & 0 \\
\hline \multicolumn{3}{|c|}{ Number of Voters } & $\begin{array}{l}1 \\
3\end{array}$ & $\mathbf{0}$ & 2 & 2 & 7 & 5 & $\begin{array}{l}2 \\
9\end{array}$ & 2 & $\mathbf{0}$ & 22 & 1 & 1 & $\mathbf{0}$ & 3 & 3 \\
\hline
\end{tabular}

Based on the choice matrices in table 2. and table 3., it can be seen that the male handball athletes who have the highest selection index are 3 (three) athletes, the first athlete is RK with an index score of election status (29), then followed by RP with a total score (22), and the 3rd place with the most election index score is DAF with an election index score (13). Whereas athletes who have the lowest selection index are PG with a total score (0), SA with a total score (0), and WI with a total election index score (0). 
Henceforth based on the selection matrix and selection index in table 3. and fig. 1 shows that the interpersonal relationship between male handball athletes is quite good, even though there are three (3) athletes who get a selection index score of zero (0) where none of the three athletes choose to be friends during training or become the leader or captain of the Handball team. Meanwhile, athletes who have the highest selection index score to be friends during training and who are considered capable of leading the team are athletes with a score of (29), namely RK.

Table 3. Index Selection Status Male Handball Team

\begin{tabular}{clccr}
\hline No. & Subjects Name & Score & Nxp & \multicolumn{2}{l}{ Index CS } \\
\hline $\mathbf{1}$ & DAF & 13 & 45 & 0,288888889 \\
\hline $\mathbf{2}$ & PG & 0 & 45 & 0 \\
\hline $\mathbf{3}$ & ANM & 2 & 45 & 0,044444444 \\
\hline $\mathbf{4}$ & AC & 2 & 45 & 0,044444444 \\
\hline $\mathbf{5}$ & JF & 7 & 45 & 0,155555556 \\
\hline $\mathbf{6}$ & AA & 5 & 45 & 0,111111111 \\
\hline $\mathbf{7}$ & RK & 29 & 45 & 0,644444444 \\
\hline $\mathbf{8}$ & MEJ & 2 & 45 & 0,044444444 \\
\hline $\mathbf{9}$ & SAM & 0 & 45 & 0 \\
\hline $\mathbf{1 0}$ & RP & 22 & 45 & 0,488888889 \\
\hline $\mathbf{1 1}$ & DW & 1 & 45 & 0,022222222 \\
\hline $\mathbf{1 2}$ & AK & 1 & 45 & 0,022222222 \\
\hline $\mathbf{1 3}$ & WI & 0 & 45 & 0 \\
\hline $\mathbf{1 4}$ & MF & 3 & 45 & 0,066666667 \\
\hline $\mathbf{1 5}$ & DP & 3 & 45 & 0,066666667 \\
\hline & & & &
\end{tabular}




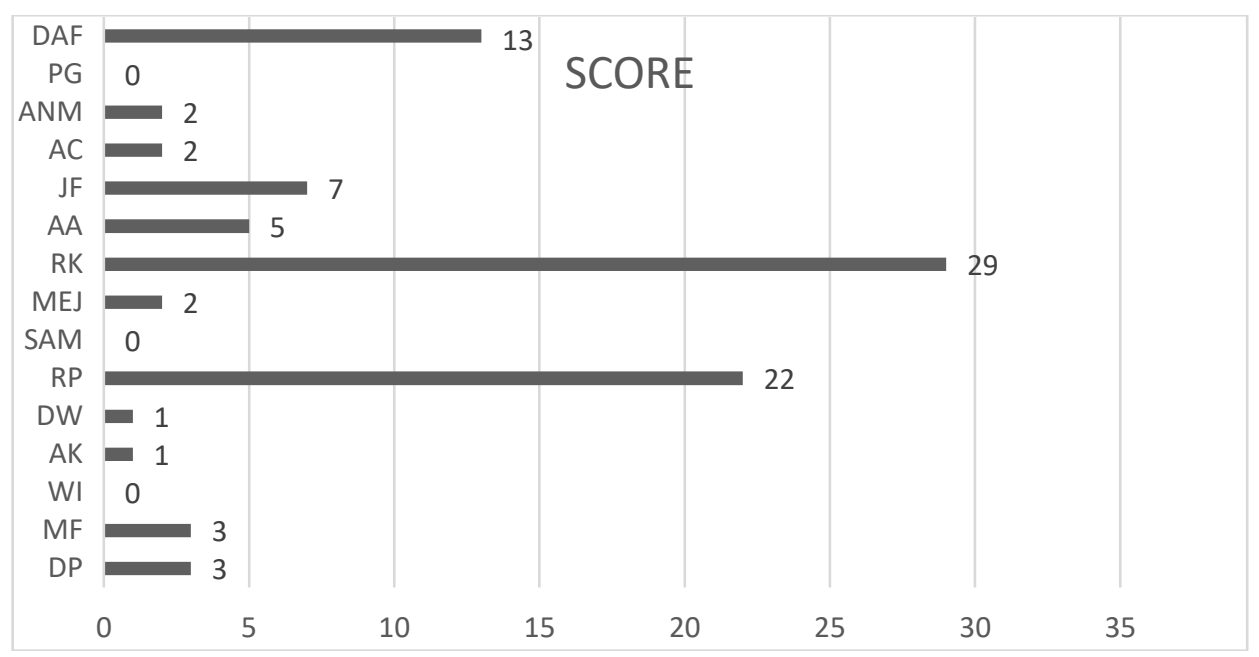

Fig. 1. Team members score selection chart

In general, the cohesiveness and harmonization relationship between athletes or players in the Male Handball Team is quite extensive, where it can be seen from the interpersonal relationships and communication that occurs including almost all members of the team / athlete. Henceforth in the selection of the sociogram shown in the fig. 2. allows to provide a comparative analysis of the structure of the interpersonal relationships in the Male Handball Team and can provide a visual representation of who is suitable to be the leader or captain and show interpersonal relationships taking into account the popularity of each team member based on the matrix and the election status index.

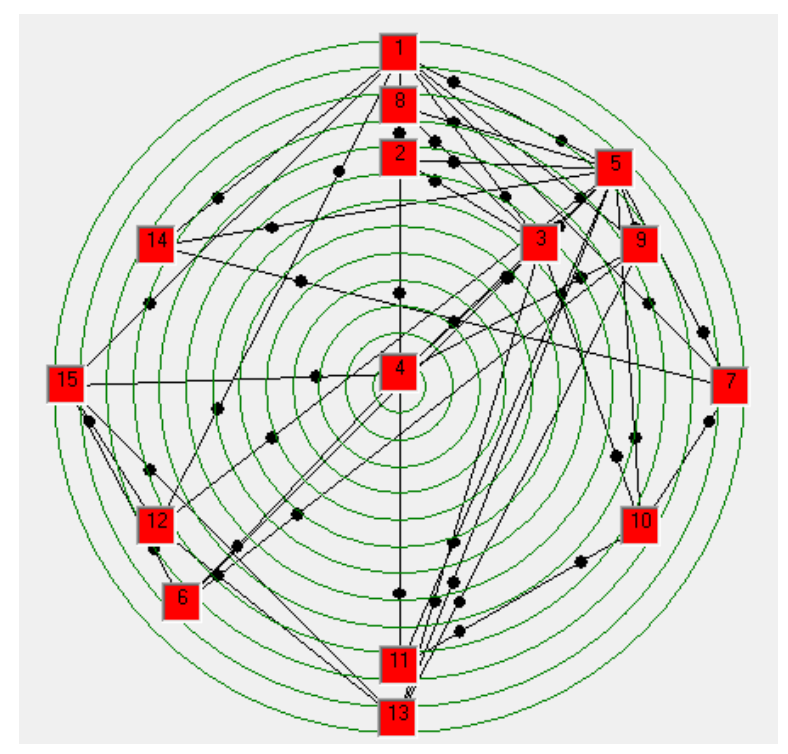

Fig. 2. Sociogram elections 
In general, the cohesiveness and harmonization relationship between athletes or players in the Male Handball Team is quite extensive, where it can be seen from the interpersonal relationships and communication that occurs including almost all members of the team or athlete. Although based on the choice matrix and the selection index, there are three athletes who get a selection index score of zero (0) where none of the three athletes choose to be friends during training or become the leader or captain of the Handball team. It is expected that over time and the development of the team, more athletes will be selected as team leaders and included in the subgroups that have average popularity.

\section{Conclusion}

Based on these results it can be concluded that the use of sociometry can measure cohesiveness, harmonization, interpersonal relationships between members of Male Handball Team. Specifically, this sociometry test is aimed at athletes with whom he wants to train together, finding the team social structure and hierarchy of each team member (team leader) using the sociometry test method proposed by Jacob L. Moreno. The results of this study provide a comparative analysis of the structure of the interpersonal relationships in the Male Handball Team and can provide a visual representation of who deserves to be a leader or captain and show interpersonal relationships by considering the popularity of each team member based on matrices and index selection status.

\section{References}

[1] Gadžić, A., \& Vučković, I. (2009). Participation in sports and sociometric status of adolescents. Biomedical Human Kinetics, 1(November 2009). https://doi.org/10.2478/v10101-009-0021-y

[2] Dontsov, D. A., \& Sagova, Z. A. (2018). Methods of social and psychological diagnostics of sports groups and groups of younger schoolchildren, adolescents and youths,School technology, 1, 89102.

[3] Vashliaeva, I. V., Volovik, T. V., \& Shuraleva, N. N. Sociometry of a volleyball team. (2019). Journal of Physical Education and Sport, 19(2), 1104-1111.

[4] Wäsche, H., Dickson, G., Woll, A., \& Brandes, U. Social network analysis in sport research: an emerging paradigm, (2017). European Journal for Sport and Society, 14(2), 138-165.

[5] Sopa, I.S. \& Pomohaci M. (2015 a). Developing Cohesion in Sportive Group through the Socializing Means of Motor Activities. Bologna: Medimond Publishing Company by Editografica, p. 135.

[6] Dontsov, D. A., \& Sagova, Z. A. (2018). Methods of social and psychological diagnostics of sports groups and groups of younger schoolchildren, adolescents and youths,School technology, 1, 89102. .

[7] Weinberg, R., \& McDermott, M. (2002). A comparative analysis of sport and business organizations: Factors perceived critical for organizational success. Journal of Applied Sport Psychology, 14(4), 282-298

[8] Herbison, J. D., Vierimaa, M., Côté, J., \& Martin, L. J. (2018). The dynamic nature of connection and its relation to character in youth sport, International Journal of Sport and Exercise Psychology, 1-10.

[9] Laver L, Landreau P, Seil R, Popovic N, Science B, Management I. Handball Sports Medicine

[10] Sopa, I. S., \& Pomohaci, M. (2018). Discovering the leader of a volleyball team using the sociometric survey method. Timisoara Physical Education \& Rehabilitation Journal, 10(3). 
[11] Timushkin, A. V., \& Kuzmin, A. M. (2018). Determining the leader in a professional team in the relationship process in a sports team. News of the Saratov University. New series. Philosophy Series. Psychology. Pedagogy, 18 (2).

[12] Sopa, I. S., \& Pomohaci, M. (2018). Discovering the leader of a volleyball team using the sociometric survey method. Timisoara Physical Education \& Rehabilitation Journal, 10(3). 